\title{
Survey of UI Design Needs for Integrated Service Apps in Large Hospitals are the Medical Industry-Based on a Case Study in Zhengzhou
}

\author{
FanYu \\ College of Arts and Design, Zhengzhou University of Light Industry, Zhengzhou, Henan, China
}

\begin{abstract}
The improvement of Service Apps has a strong driving effect on the overall improvement of the medical industry. Besides, it is more conducive to the prevention and control of the COVID-19 outbreak for patients with chronic and mild diseases to use the online inquiry. Therefore, in this paper, the status quo of comprehensive service design for large-scale hospitals in Zhengzhou, China is analyzed and summarized, and the necessary requirements for establishing a unified UI (User Interface) design centered on users (patients) are studied, in order to enhance and improve the design content of inappropriate placement and use of UI.Using the existing model of integrated services, an evaluation project is proposed for users. A survey study is made on investigating the needs for UI design in large general hospitals from a service perspective based on relevant theories, which aims to achieve enhancement of the hospital system, reach work productivity and increase brand-name value of hospital services. It involves the lack of unity of information systems and user confusion due to the different forms. To solve this problem, user-centric UI design includes a coherent interface, an experiential design component, and a visual component. Therefore, in this study, the network service App and UI design needs of large hospitals in Zhengzhou City are investigated and summarized.Based on the situational design method, the user centered design fully considers the user needs in different situations and gives feedback, so as to improve the user experience. The integrated design model of service design created in this study will help large general hospitals in Zhengzhou to establish organic, efficient and high-quality health care services, and realize a general hospital system to improve service experience and service satisfaction for all users.
\end{abstract}

Keywords:Medical industry, UI Design, Service Apps

\section{Introduction}

\subsection{Background}

With the development of information technology, large hospitals committed themselves to developing intelligent systems to meet the trend of the times. The new medical policy reform in China since 2016 [1] not only improves medical technology but also promotes the development of high-quality medical services. In the future, the development of medical services is a combination of technology industry and Internet innovation, which means more health-related services need to be improved for patients. People are increasingly in need of diversified, individualized and continuous health services. However, at present, domestic medical service system is relatively short of resources, and the growing contradiction between supply and demand is becoming more and more prominent.

As "Internet + medical treatment" played an active role in the state of social traffic control during the COVID-19 epidemic, public hospital institutions also started to promote the construction of hospital Official Accounts and Alipay online treatment module, covering a number of functions such as medical policy publicity, health education, online registration, online examination, drug mailing[2]. Although "Internet + medical treatment" has made rapid breakthroughs in technology, the research on the role of its new service model in the transformation of residents' health service needs into needs is relatively less, lacking of social, psychological and other aspects of thinking and analysis of residents. 


\subsection{Objectives}

Therefore, in this study, in the patient-centered, user-centered service area, the hospital UI design integrates medical technology and service elements in order to make it easier and more convenient for patients to obtain the required information, including the elderly, children, disabled and other users who are unable to adapt to the new technology. Furthermore, the need for collaboration in system UI and hospital system UI design is explored in the field of hospital service design. In addition, the design of comprehensive service in large-scale hospitals in Zhengzhou City, Henan Province is studied, the existing hospital system is integrated, and the UI redesign (Re-Design) is carried out according to the needs, and the necessary elements for UI design are proposed through the development model.

\section{Scope and Method}

By analyzing the UI errors and problems encountered by hospital users (i.e., patients or hospital users) in the process of introducing hospital information system, this study puts forward the scope and model of the integrated service design, focusing on the current situation and existing research of service design in large hospitals at home and abroad, providing necessary conditions for UI design.

Based on the current situation of network inquiry APPs in 10 Class A tertiary [3] hospitals in Zhengzhou City, Henan Province, China, this study analyzes the visual elements and design elements of hospital system UI design according to the contextualized design method centering on users.

\section{III.Previous Research on UI Design in Hospitals}

UI (user interface) is a dictionary term designated as a design or result that provides an environment in which a user can easily and conveniently use a computer program or a mobile machine [4], with the consequent goal of easy and convenient use, all of which focuses on the user.

Therefore, user-centered design is the basic element of UI, which must include communication element, which is also very important in hospital UI design elements. Physicians, patients, employees, and users other than patients must be able to use them fluently, and the system built for the purpose of waiting time and working efficiency must be able to achieve its goal. To this end, screen composition in service design areas such as kiosks and applications must be user-centered, i.e. UI design. People of all ages should be able to use the device easily and conveniently and naturally reuse it when accessed again, so UI design must have high information visibility and eliminate errors in information retrieval and input. In addition, appropriate visual grouping is required, as correct grouping not only reduces the identification and input time of information users, but also forms a visual hierarchy, thus reducing user perception errors due to information hierarchy.

UI requirements for hospital communications services: reliability, consistency, accessibility and appearance are important, which further emphasizes it functions as a communication element, including UX (User Experience) requirement [5].

\section{IV.Requirements for Integrated Design of UI Services in Large Hospitals}

According to the related previous research, the change of service is divided into intangible, tangible and visual trends through design [5]. Table 1 is service design has changed from an intangible service form to a visual form that provides rapid information and intuitive understanding, thus becoming a tangible and intangible design, which standardizes the availability and content that are easy to identify, and makes the service commercial, thus providing consumers with a new experience. 
Table 1Analysis of service elements of UI design

\begin{tabular}{|c|c|c|}
\hline General features of services & Change through service design & $\begin{array}{c}\text { Expectations for product service } \\
\text { design }\end{array}$ \\
\hline Intangible & Tangible & Visualization \\
\hline Invisible services & $\begin{array}{c}\text { Transfer of abstract values in a visible } \\
\text { form }\end{array}$ & $\begin{array}{c}\text { Fast information transfer and intuitive } \\
\text { understanding of tangible and } \\
\text { intangible design }\end{array}$ \\
\hline Heterogeneous & Consistent & Standardization \\
\hline $\begin{array}{c}\text { Varied customer experience even } \\
\text { with the same services }\end{array}$ & $\begin{array}{c}\text { Consistently delivering everything } \\
\text { that customers can experience }\end{array}$ & $\begin{array}{c}\text { Consistent and identifiable } \\
\text { availability and content }\end{array}$ \\
\hline $\begin{array}{c}\text { Perishable } \\
\text { feature of disappearing at the same } \\
\text { time. }\end{array}$ & $\begin{array}{c}\text { Providing customers with a } \\
\text { non-temporary and lasting experience }\end{array}$ & $\begin{array}{c}\text { Providing an integrated experience } \\
\text { through product services and service } \\
\text { productization }\end{array}$ \\
\hline
\end{tabular}

Mobile medicine refers to the provision of medical services and information by using mobile communication technology, and the value of its related products is reflected in a significant reduction in individual visits and in the pressure on hospitals and society [4] in the faster pace of life today. However, the existing mobile medical products in the market have serious homogeneity, poor user experience and poor user stickiness, so developers should fully consider the emotional design factors in the design process to bring users a better interactive experience. At present, according to the user orientation of mobile medical Apps in China, the existing products on the market can be divided into three categories:

Category I: Integrated Medical and Health Information Services, which are targeted at a large base of patients, such as those with diabetes, heart disease, etc. Users can input their symptoms and health index into the corresponding user data within the product to complete personal account binding. After that, the product will recommend relevant information about the disease to users, including a series of related services such as basic prevention and control, drug recommendation, online consultation, hospital registration, etc. Some products also cooperate with insurance companies to make profits.

Category II: Query Professional Medical Data, which are targeted at medical practitioners and physicians. Users can retrieve medical literature or research reports on this platform, and at the same time, write articles in the medical industry and exchange academic discussions and clinical experience among medical professionals.

Category III: Medical Product Services, which can be classified as Transactional Apps, are targeted at the urban population as well as patients with chronic disease. Urban people living at a fast pace can purchase over-the-counter medicines through commercial logistics network to solve their needs without delay, while patients with chronic diseases, due to the large demand for medication, can online purchase commonly used drugs after uploading the prescription certificate for review.

\section{Analysis on APP Usage in 10 Large Hospitals in Zhengzhou}

According to the survey, the 'internet' plus network hospital form has been adopted in 10 Class A tertiary hospitals in Zhengzhou, which enables doctors to carry out remote outpatient service, remote consultation and two-way referral together with primary hospitals and higher-level hospitals through computers, mobile terminals and special equipment, for medical record analysis and disease diagnosis of patients[6]. For patients with long distances, network hospitals provide remote outpatient consultation services, so that first-time patients can initiate remote outpatient consultation by binding the treatment card with APP and real-name authentication, and filling in the detailed information of the patient, disease description and related pictures, report materials, etc. when registering, which is mainly to answer patients' daily health problems online, and realize doctors' online rapid response [7]. According to the concept and requirements of remote outpatient service in Opinions of National Health and Family Planning Commission on Promoting Telemedicine Service in Medical Institutions, remote outpatient service, as a

ISSN: 0010-8189 
way for doctors in primary hospitals to apply for remote consultation with higher-level hospital experts, discuss patients' conditions together and formulate more targeted treatment plans[8], can effectively relieve the pressure of outpatient service and provide patients with an efficient, convenient and equal experience.

Based on the retrieval of mobile application platforms (including iphone and Android systems), two of Zhengzhou's 10 large public hospitals have independent network hospital APPs, and two of China's largest medical platforms (Ping An Good Doctor and Chunyu Doctor) have online doctor inquiries at Henan Provincial People's Hospital and the First, Fifth and Second Affiliated Hospitals of Zhengzhou University, while the other seven hospitals only have online doctor inquiries at Ping An Good Doctor. The 10 hospitals all have their own WeChat official accounts and all work on the government-developed APP (Henan Provincial Reservation Registration Service Platform), but they are only limited to basic services such as online registration without in-depth online consultation, joint diagnosis and drug purchase. Table 2 is a comparative study of the network service development projects of 10 large hospitals in Zhengzhou, Henan Province.

Table 2 Summarize the service APP of large hospitals in Zhengzhou

\begin{tabular}{|c|c|c|c|c|c|c|}
\hline $\mathbf{S} / \mathbf{N}$ & Names & Independent APPs & $\begin{array}{l}\text { Independent } \\
\text { LOGOs }\end{array}$ & $\begin{array}{c}\text { Government-developed } \\
\text { APPs }\end{array}$ & $\begin{array}{l}\text { WeChat } \\
\text { official } \\
\text { accounts }\end{array}$ & $\begin{array}{c}\text { Other } \\
\text { platforms }\end{array}$ \\
\hline $\mathbf{1}$ & $\begin{array}{l}\text { Henan Provincial } \\
\text { People's Hospital }\end{array}$ & $\begin{array}{l}\text { Henan Provincial } \\
\text { People's Hospital }\end{array}$ & & $\begin{array}{l}\text { Henan Provincial Reservation } \\
\text { Registration Service Platform }\end{array}$ & $\begin{array}{l}\text { Henan } \\
\text { Provincial } \\
\text { People's } \\
\text { Hospital }\end{array}$ & $\begin{array}{l}\text { Ping An Good } \\
\text { Doctor and } \\
\text { Chunyu Doctor }\end{array}$ \\
\hline 2 & $\begin{array}{l}\text { The First } \\
\text { Affiliated } \\
\text { Hospital of } \\
\text { Zhengzhou } \\
\text { University }\end{array}$ & $\begin{array}{c}\text { Online Hospital of } \\
\text { the First Affiliated } \\
\text { Hospital of } \\
\text { Zhengzhou } \\
\text { University }\end{array}$ & & $\begin{array}{l}\text { Henan Provincial Reservation } \\
\text { Registration Service Platform }\end{array}$ & $\begin{array}{l}\text { The First } \\
\text { Affiliated } \\
\text { Hospital of } \\
\text { Zhengzhou } \\
\text { University }\end{array}$ & $\begin{array}{l}\text { Ping An Good } \\
\text { Doctor and } \\
\text { Chunyu Doctor }\end{array}$ \\
\hline 3 & $\begin{array}{c}\text { Zhengzhou } \\
\text { Central Hospital } \\
\end{array}$ & I & I & $\begin{array}{l}\text { Henan Provincial Reservation } \\
\text { Registration Service Platform } \\
\end{array}$ & \begin{tabular}{|c|} 
Zhengzhou \\
Central Hospital \\
\end{tabular} & \begin{tabular}{|c|}
$\begin{array}{c}\text { Ping An Good } \\
\text { Doctor }\end{array}$ \\
\end{tabular} \\
\hline 4 & $\begin{array}{c}\text { The Third } \\
\text { Affiliated } \\
\text { Hospital of } \\
\text { Henan } \\
\text { University of } \\
\text { Chinese } \\
\text { Medicine } \\
\end{array}$ & l & I & $\begin{array}{l}\text { Henan Provincial Reservation } \\
\text { Registration Service Platform }\end{array}$ & \begin{tabular}{|c|} 
The Third \\
Affiliated \\
Hospital of \\
Henan \\
University of \\
Chinese \\
Medicine \\
\end{tabular} & $\begin{array}{l}\text { Ping An Good } \\
\text { Doctor }\end{array}$ \\
\hline 5 & $\begin{array}{c}\text { Zhengzhou } \\
\text { T.C.M. Hospital }\end{array}$ & I & I & $\begin{array}{l}\text { Henan Provincial Reservation } \\
\text { Registration Service Platform }\end{array}$ & \begin{tabular}{|c|} 
Zhengzhou \\
T.C.M. Hospital \\
\end{tabular} & $\begin{array}{c}\text { Ping An Good } \\
\text { Doctor }\end{array}$ \\
\hline 6 & $\begin{array}{l}\text { Henan Province } \\
\text { Hospital of TCM }\end{array}$ & / & I & $\begin{array}{l}\text { Henan Provincial Reservation } \\
\text { Registration Service Platform }\end{array}$ & \begin{tabular}{|c|} 
Henan Province \\
Hospital of \\
TCM \\
\end{tabular} & $\begin{array}{l}\text { Ping An Good } \\
\text { Doctor }\end{array}$ \\
\hline 7 & $\begin{array}{c}\text { The First } \\
\text { Affiliated } \\
\text { Hospital of } \\
\text { Henan } \\
\text { University of } \\
\text { Chinese } \\
\text { Medicine }\end{array}$ & I & I & $\begin{array}{l}\text { Henan Provincial Reservation } \\
\text { Registration Service Platform }\end{array}$ & \begin{tabular}{|c|} 
The First \\
Affiliated \\
Hospital of \\
Henan \\
University of \\
Chinese \\
Medicine \\
\end{tabular} & $\begin{array}{l}\text { Ping An Good } \\
\text { Doctor }\end{array}$ \\
\hline 8 & $\begin{array}{c}\text { Zhengzhou } \\
\text { People's Hospital }\end{array}$ & I & I & $\begin{array}{l}\text { Henan Provincial Reservation } \\
\text { Registration Service Platform }\end{array}$ & $\begin{array}{c}\text { Zhengzhou } \\
\text { People's } \\
\text { Hospital } \\
\end{array}$ & $\begin{array}{l}\text { Ping An Good } \\
\text { Doctor }\end{array}$ \\
\hline 9 & $\begin{array}{l}\text { The Fifth } \\
\text { Affiliated } \\
\text { Hospital of } \\
\text { Zhengzhou } \\
\text { University } \\
\end{array}$ & l & I & $\begin{array}{l}\text { Henan Provincial Reservation } \\
\text { Registration Service Platform }\end{array}$ & $\begin{array}{l}\text { The Fifth } \\
\text { Affiliated } \\
\text { Hospital of } \\
\text { Zhengzhou } \\
\text { University }\end{array}$ & $\begin{array}{l}\text { Ping An Good } \\
\text { Doctor and } \\
\text { Chunyu Doctor }\end{array}$ \\
\hline 10 & $\begin{array}{l}\text { The Second } \\
\text { Affiliated } \\
\text { Hospital of } \\
\text { Zhengzhou } \\
\text { University }\end{array}$ & I & I & $\begin{array}{l}\text { Henan Provincial Reservation } \\
\text { Registration Service Platform }\end{array}$ & $\begin{array}{l}\text { The Second } \\
\text { Affiliated } \\
\text { Hospital of } \\
\text { Zhengzhou } \\
\text { University }\end{array}$ & $\begin{array}{l}\text { Ping An Good } \\
\text { Doctor and } \\
\text { Chunyu Doctor }\end{array}$ \\
\hline
\end{tabular}




\section{Analysis on UI Design in Large Hospitals}

To accurately perform the services required by patients and protect the reliability of patients' personal information, the color, text and visual elements of the whole screen of GUI (Graphical User Interface) perspective must be unified and consistent, and the accessibility and difference of information is an aesthetic that can provide users with emotional satisfaction through the conciseness and emotional consideration of UI, which is not only simply conveying information, but the accessibility emphasizes visual elements or minimizes the scope of errors[9].

The visual part of the interface, called graphical user interface (GUI) [10], has basic items including color, layout, format, graphics, multimedia and navigation. Based on previous research, the GUI part is transplanted to the model of service integration design UI requirements development, which is a part of UI requirements, and needs both necessity and importance in user-centered service design.

The analysis on APP content in Henan Provincial People's Hospital and the First Affiliated Hospital of Zhengzhou University is shown in the following table 3.

Table 3 Analysis of the UI design of Henan Provincial People's Hospital and the First Affiliated Hospital of Zhengzhou University

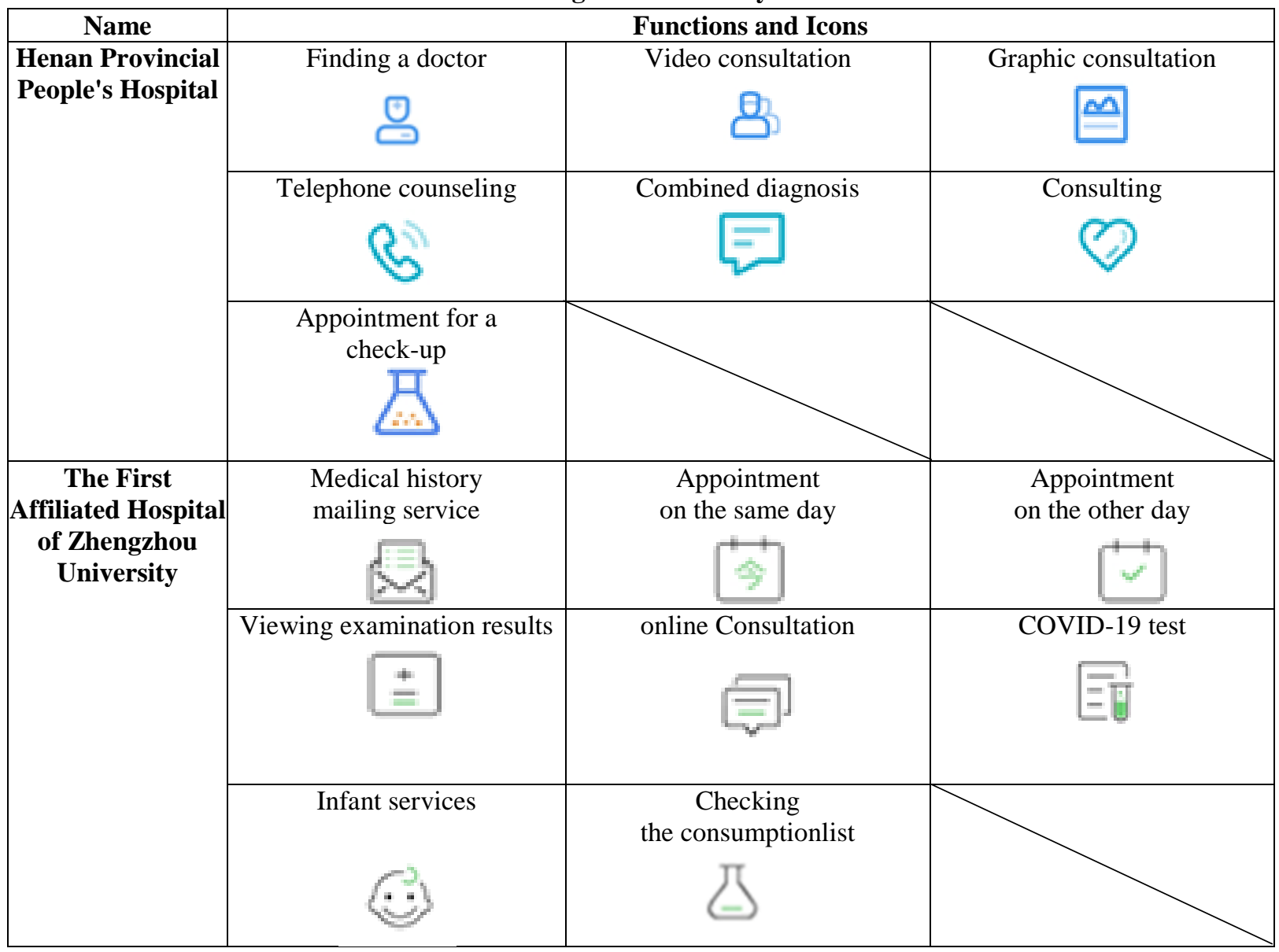

According to incomplete statistics of mobile phone platforms, Henan Provincial People's Hospital App has been downloaded for about 80,000 times, and The First Affiliated Hospital of Zhengzhou University App for about 70,000 times. Based on the iPhone system, the comprehensive score of Henan Provincial People's Hospital App is 3.4 points, and that of the First Affiliated Hospital of Zhengzhou University is 3.5 points.

Judging from the different in-app UI design interfaces of the two hospitals, the hospital that is more suitable for the ISSN: 0010-8189 
current epidemic prevention and control work in COVID-19 is the First Affiliated Hospital of Zhengzhou University, because the UI interface has specific items for COVID-19 testing applications and appointments for the same day and other times. However, the video consultation service of Henan Provincial People's Hospital can also greatly alleviate the number of people going to the hospital.

According to the user positioning of mobile medical App in China, the apps of Henan Provincial People's Hospital and the First Affiliated Hospital of Zhengzhou University are comprehensive apps containing existing product types in the market, which are more focused on the use of patients in their own hospitals.

\section{VII.Proposal}

According to the survey of network services of 10 large general hospitals in Zhengzhou, it is found that the only hospitals with independent App are Henan Provincial People's Hospital and the First Affiliated Hospital of Zhengzhou University, which are also the two hospitals with the strongest comprehensive strength in scientific research and service with relatively mature and perfect App systems. However, the First Affiliated Hospital of Zhengzhou University received a higher degree of praise and paid more attention to the prevention and control of COVID-19 epidemic.

According to this study, the ultimate goal of integrating service design with this development model and UI requirements model is to:

-improve hospital services and increase patient satisfaction;

-increase hospital care income, reduce labor costs;

-improve work efficiency;

-improve accuracy, speed and ease of information selection;

-increase hospital brand value.

The following proposals and suggestions are put forward for App design of 10 large general hospitals in Zhengzhou:

-Establish an App for independent use that closely aligns with the hospital's treatment, service and scientific research work;

-Combine the comprehensive medical and health information services, inquiry professional medical information and pharmaceutical products and services with the user positioning of the mobile medical App in China;

-Establish a medical resource sharing system for large-scale hospitals in Zhengzhou to realize network resource allocation;

-Make integrated design for network consultation, medical treatment, purchase of drugs;

-Enhance the value of hospital brand in Zhengzhou.

Hospital service is a service design that gradually provides high-quality medical services, because a hospital optimized by design means can not only improve satisfaction, but also protect patients, reduce waiting time, and reduce redundant work and errors, which will promote the overall satisfaction of medical services and so on. Moreover, because of the job satisfaction and labor cost saving, the brand value and recognition of the hospital by the patients will also be appreciated.

In the development of various types of technologies and solutions, the importance of the unity of UI design and service design of current hospital information systems has become increasingly prominent, and ubiquitous system problems such as existing information kiosks and applications as well as UI design have been improved and applied. In doing so, it is believed that a unified guideline is needed so that new solutions to be introduced can be well integrated. In addition, the service design designed by the service integration design development model is expected to become a guide to mutually organic and effective high quality medical service in the future hospital era. In the next step, aiming at the regional characteristics and human customs of Zhengzhou, the UI design of App in large hospitals in Zhengzhou will be model developed and studied.

ISSN: 0010-8189 


\section{References}

[1] H.F. Yu, "Introduction of Chinese Medical Insurance System into Market Mechanism Reform," PhD Dissertation of Graduate School of Chinese Academy of Social Sciences, 201705.

[2] F. Li, Y. Zhang, "An Analysis of the Functional Path of Internet+Medical Treatment Affecting the Utilization of Health Services for Residents," Medicine and Society, 202103.

[3] "Class A tertiary hospitals are the highest-level hospitals in the mainland of China, which are classified according to the current," The measures for the administration of the hospital grade and other regulations.

[4] Y. Wen, "UI Design of Mobile Internet Software Products," ShandongUniversity, 201308.

[5] Y.Q. Sun, "Design and Implementation of Registration APPs for Hospitals," Nanjing University of Science and Technology, 201812.

[6] X.Y. Wang, "Case Analysis and Research of Emotional Design-based Mobile Medical Apps," Popular Literature and Art, 202011.

[7] J. Hyun Lee, "A Study on Investigating UI Requirements for Integrated Service Design of Large-ScaleHospitals,”A Journal of Brand Design Association of Korea, 201609.

[8] L.H. Zhi, M.Y. Xing, G.Q. Wei, et al., "Construction of "Patient-centered" Internet Hospital Service Model in Large General Hospitals," Modern Hospital, 202010.

[9] W.Z. Yuan, C.P. Wang, X.W. Lin, Yong'an Deng, "Construction and Application of Internet Hospital in New Period," Journal of Medical Informatics, 202010.

[10] Q.B. Yang, S.Q. Huang, "Exploration and Practice on Internet Hospital Construction based on a Case Study of Fujian Provincial Government Hospital,” Management Observer. 